\title{
The added value from a general equilibrium analysis of increased efficiency in household energy use
}

\author{
Patrizio Lecca $^{1}$, Peter G. McGregor ${ }^{1}$, J. Kim Swales ${ }^{1}$ and Karen Turner ${ }^{2, a}$
}

\section{Fraser of Allander Institute, Department of Economics and Strathclyde International}

Public Policy Institute, University of Strathclyde

2. Centre for Energy, Resource and Environmental Studies and Department of Accounting, Economics and Finance, School of Management and Languages, Heriot Watt University. a. Corresponding author: K.Turner@hw.ac.uk.

\section{Acknowledgments}

The authors gratefully acknowledge the financial support of the ESRC through a First Grants project (ESRC ref: RES-061-25-0010), the EPSRC's Highly Distributed Energy Futures Consortium (EPSRC ref: EP/G031681/1) and funding from the Scottish Government through ClimateXChange. 


\title{
The added value from a general equilibrium analysis of increased efficiency in household energy use
}

\begin{abstract}
This paper investigates the economic impact of a 5\% improvement in UK household energy efficiency, focussing specifically on total energy rebound effects. The impact is measured through simulations using models that have increasing degrees of endogeneity but are calibrated on a common data set, moving from a basic partial equilibrium approach to a fully specified general equilibrium treatment. The size of the rebound effect is shown to depend on changes in household income, aggregate economic activity and relative prices that can only be captured through a general equilibrium model.
\end{abstract}

Keywords: Energy efficiency; indirect rebound effects; economy-wide rebound effects; household energy consumption; CGE models.

JEL codes: C68, D57, D58, Q41, Q43, Q48 


\section{Introduction}

There has been extensive investigation of the economy-wide rebound effects resulting from energy efficiency improvements in production. This analysis often uses a computable general equilibrium (CGE) modelling approach (see Dimitropoulos, 2007; Sorrell, 2007; and Turner 2013 for a review). However, very few studies have attempted to measure the economy-wide impacts of energy efficiency improvements in the household sector. Following the work of Khazzoom $(1980,1987)$ there have been a numbers of partial equilibrium studies (Dubin et al. 1986; Frondel et al. 2008; Greene et al. 1999; Klein, 1985 and 1987; Nadel, 1993; Schwartz and Taylor, 1995; West, 2004). Further, Greening et al. (2000) gives a detailed and extensive summary of the extent of rebound on household consumption of different types of energy services. These studies assume that there are no changes in prices or nominal incomes following the efficiency improvement, and that the impacts are limited to the direct market for household energy use. This approach gives an extreme partial equilibrium figure, which is generally known as the direct rebound effect.

To our knowledge, Dufournaud et al. (1994) is the only study that investigates full general equilibrium economy-wide rebound effects from increased energy efficiency in the household sector. It examines the impacts of increasing efficiency in domestic wood stoves in Sudan. Druckman et al. (2011), Freire-Gonzalez (2011) and Thomas and Azevedo (2013a; 2013b) use a fixed price input-output model to consider indirect rebound effects resulting from household income freed up by energy efficiency improvements and spent on non-energy commodities. This work includes changes in energy use in production, as well as household consumption. However, we still treat this as a partial equilibrium approach as it fails to incorporate endogenous prices, incomes or factor supply effects. 
The aim of the present paper is to identify the added value from using general equilibrium techniques to consider the economy-wide impacts of increased efficiency in household energy use. We take as an illustrative case the effect of a 5\% improvement in UK household energy efficiency. The subsequent impact on energy use is measured through simulations employing models that have increasing degrees of endogeneity but are all calibrated on a common data set. That is to say, we calculate rebound effects for models that progress from the most basic partial equilibrium approach to a fully specified general equilibrium treatment.

\section{Rebound Effects}

We categorise an increase in household energy efficiency as being a change in household "technology" that increases the energy services generated by each unit of physical energy consumed. An alternative way of expressing this is that the energy value in efficiency units has risen. ${ }^{1}$ This implies that the original level of household utility can be achieved through the consumption of the original levels of other household goods and services, but with a lower consumption of energy. $^{2}$

We define the rebound effect as a measure of the difference between the proportionate change in the actual energy use and the proportionate change in energy efficiency. This difference is primarily driven by the fact that, ceteris paribus, an increase in the efficiency in a particular energy use reduces the price of energy in that use, measured in efficiency units. This reduction then leads consumers to substitute energy, in efficiency units, for other goods and services implying that the proportionate reduction in energy use is typically less than the

\footnotetext{
${ }^{1}$ We discuss in Section 3 how such efficiency improvements might come about.

${ }^{2}$ We do not identify an improvement in household energy efficiency as simply a reduction in the direct energy intensity of consumption. For example, a fall in household energy use generated by an increase in the price of energy (through a carbon tax, for example) would not count as an improvement in household energy efficiency.
} 
proportionate improvement in energy efficiency. ${ }^{3}$ This is the rebound effect. Moreover, in principle, energy use can actually rise in these circumstances, if its use is sufficiently price sensitive. This is known as backfire (Khazzoom, 1980 and 1987).

In the case under consideration here, for a proportionate improvement in household energy use of $\gamma$, rebound in the household consumption of energy, $R_{C}$, can be calculated as:

$$
R_{C}=\left[1+\frac{\dot{E}_{C}}{\gamma}\right] \cdot 100
$$

where $\dot{E}_{C}$ is the proportionate change in energy use in household consumption, which may be positive or negative.

We are also interested in the economy-wide rebound of household energy efficiency improvements: that is to say, the impact on energy use in the economy as a whole, both in consumption and production. ${ }^{4}$ The total rebound formulation used in this case, $\mathrm{R}_{\mathrm{T}}$, is given as:

$$
R_{T}=\left[1+\frac{\dot{E}_{T}}{\alpha \gamma}\right] \cdot 100
$$

where $\alpha$ is the initial share of household energy consumption in total energy use. The term $\frac{\dot{E}_{T}}{\alpha \gamma}$ can be expressed as:

$$
\frac{\dot{E}_{T}}{\alpha \gamma}=\frac{\Delta E_{T}}{\gamma E_{C}}=\frac{\Delta E_{C}+\Delta E_{P}}{\gamma E_{C}}=\frac{\dot{E}_{C}}{\gamma}+\frac{\Delta E_{P}}{\gamma E_{C}}
$$

\footnotetext{
${ }^{3}$ The distinction between energy quantities and prices measured in natural and efficiency units is important in explaining how the rebound effect operates. However, in the present paper, unless we explicitly state otherwise, energy is being measured in natural units.

${ }^{4}$ Our interest here is limited to the rebound effect within the target economy, so that we abstract from potential spillover effects to other countries.
} 
where $\Delta$ represents absolute change and the $P$ subscript indicates production. Substituting equations (1) and (3) into equation (2) gives:

$$
R_{T}=R_{C}+\frac{\Delta E_{P}}{\gamma E_{C}} \cdot 100
$$

This shows that the total rebound will be higher (lower) than the consumption rebound if the energy use in production increases (decreases) as a result of energy efficiency improvements in consumption.

\section{Data and elasticity of substitution of energy use in consumption}

In this paper we identify the additional precision achieved through moving from a partial to a general equilibrium analysis of the rebound effects. We consider the specific case of energy efficiency improvements in household consumption. ${ }^{5}$ We quantify the rebound effect through simulation using a given data set which provides common structural characteristics across all the models. Specifically we use a specially constructed UK symmetric industry-by-industry Input-Output (IO) table based on the published 2004 UK Supply and Use accounts. ${ }^{6}$ Import data in Input-Output format were provided by colleagues at the Stockholm Environment Institute. The Input-Output accounts are aggregated to identify 21 economic activities (commodities/sectors). Table 1 gives the sectoral disaggregation, separately identifying the four energy sectors; coal, oil, gas and electricity.

Table 2 identifies the energy input requirement for each of the production sectors and the energy-output multiplier effects expressed in monetary terms. That is to say, for each sector we measure the direct and indirect increase in the value of output in energy industries

\footnotetext{
${ }^{5}$ We increase household efficiency in the use of all sources of energy: coal, oil, gas and electricity.

${ }^{6}$ See http://www.strath.ac.uk/fraser/research/2004ukindustry-byindustryanalyticalinput-outputtables/ for details.
} 
generated by a unit increase in the final demand for that sector. The energy requirements are represented by the appropriate direct Input-Output coefficients (the A matrix entries) while the energy-output multipliers are the corresponding entries in the Type I Leontief inverse, [1$\mathrm{A}^{-1}$ inverse matrix. To calibrate the Computable General Equilibrium model, the conventional Input-Output accounts are augmented with all other transfer payments to form the 2004 UK Social Accounting Matrix. ${ }^{7}$ In all the analysis we use a single initial household consumption vector given in UK 2004 Input-Output accounts.

A key parameter that drives rebound analysis is the elasticity of substitution between aggregate energy and non-energy goods and services in the household's utility function. In each of the models we use, household utility, $C$, in any period is given by:

$$
C=\left[\delta^{E}\left(\gamma E_{C}\right)^{\frac{\varepsilon-1}{\varepsilon}}+\left(1-\delta^{E}\right) N E_{C}^{\frac{\varepsilon-1}{\varepsilon}}\right]^{-\frac{\varepsilon}{\varepsilon-1}}
$$

$N E_{C}$ is the consumption of non-energy commodities, $\varepsilon$ is the elasticity of substitution between energy and non-energy commodities in consumption and $\delta^{E} \in(0,1)$ is the share parameter. We estimate the value of the elasticity of substitution using UK household consumption data from 1989 to 2008 employing the conventional generalized maximum entropy (GME) method (Golan et al. 1996). ${ }^{8}$ Details of the estimation procedure are reported in Lecca et al (2011, 2013b). The short- and long-run elasticities of substitution are estimated as 0.35 and 0.61 respectively. Our elasticity estimates are broadly in line with previous empirical evidence for UK households (e.g. Baker and Blundell, 1991 and Baker et al. 1989). ${ }^{9}$

\footnotetext{
${ }^{7}$ For more information on Input-Output accounts and Social Accounting Matrices see Miller and Blair (2009).

${ }^{8}$ The value of the elasticity of substitution is likely to vary across types of energy services, such as personal transportation, residential space heating, etc. However, at this stage, for pedagogic reasons, we impose a common value across all household consumption energy uses.

${ }^{9} \mathrm{GME}$ estimation is a widely used technique for generating parameter estimates for CGE models, though for comparative purposes OLS estimates are also reported in Lecca et al, (2013b).
} 
We have estimated the substitution elasticities by observing the reaction of household energy consumption to changes in energy price. However, the question arises as to whether the same substitution elasticities are appropriate where efficiency improvements reduce the price of energy, measured in efficiency units? The answer might lie in the nature of the efficiency improvement. We see no reason not to use the long-run elasticity of substitution where longrun simulations are performed. However, for short-run simulations it might be appropriate, in some circumstances, to use the long-run elasticity value.

The short-run adjustment in household consumption of energy in response to a change in energy prices might be lower than the long-run value for two different reasons. First, there might simply be be a degree of inertia in the consumption response. However, a second reason might be that a full adjustment to the new energy price requires an investment in consumer durable goods, which only occurs in the long run.If the difference between the short and long-run elasticities is primarily due to this second reason, and household energy efficiency improvements are embedded in the design of consumer durables, it is appropriate to use long-run substitution elasticities, even for short-run simulations. This is because to access the efficiency improvement at all requires adjustment to the household capital stock which is essentially a long-run adjustment.

\section{A partial equilibrium framework}

In our partial equilibrium analysis, we assume that the prices of all commodities and services, including energy prices, are fixed and that there is no change in household nominal income. This is the impact that would be appropriate for analysing the decision by a single household to introduce improvements in energy efficiency. However, although we focus on an 
improvement in energy efficiency in consumption, we are also interested in the subsequent impact on energy use in production too. This can be achieved, whilst still maintaining the partial equilibrium assumptions of fixed prices and household income, through the application of conventional Type I Input-Output analysis.

\subsection{Household energy use}

To determine the level of rebound in household energy use, first we need to derive the elasticity of demand, $\eta$, from the elasticity of substitution, $\varepsilon$. This is given as:

$$
\eta=\varepsilon-(\varepsilon-1) \lambda
$$

where $\lambda$ is the share of energy in household expenditure (Gørtz, 1977). From the UK 2004 Input Output accounts, $3 \%$ of household consumption is spent on energy so that $\lambda=0.03$. Given elasticities of substitution reported in Section 3, the short- and long-run energy price elasticities calculated using equation (6) equal 0.37 and 0.62. Note that the long-run elasticity is consistent with estimates elsewhere in the literature for transport and nontransport related household activities (Fouquet, 2012; Fouquet and Pearson, 2012).

With no change in the price of energy, a proportionate increase in efficiency in household energy consumption, $\gamma$, generates an equal proportionate reduction in the price of energy to consumers, measured in efficiency units. If the elasticity of demand for energy is $\eta$, where $\eta$ takes a positive sign, the proportionate change in consumer energy demand, measured in efficiency units, $\dot{E}_{C}^{F}$, is given as:

$$
\dot{E}_{C}^{F}=\gamma \eta
$$

The proportionate change in consumer energy use, measured in natural units, is the proportionate change in efficiency units minus the change in efficiency: 


$$
\dot{E}_{C}=\eta \gamma-\gamma=(\eta-1) \gamma
$$

where $\eta \geq 0$ and $\frac{\partial \dot{E}_{C}}{\partial \eta}=\gamma>0$.

Substituting expressions (6) and (8) into equation (1) produces:

$$
R_{C}=100 \eta=100(\varepsilon-(\varepsilon-1) \lambda)
$$

Using the short- and long-run demand elasticities produces the short- and long-run household consumption rebound values of $36.9 \%$ and $62.2 \%$. These values are entered in the top row of Table 3. Equation (9) calculates what is conventionally known as the direct rebound. ${ }^{10}$ These figures lie within the range of available US and European estimates for specific household energy uses (Freire-Gonzales, 2010; Greening et al., 2000). A comprehensive review of empirical estimates of direct rebound effects is provided by Sorrell et al. (2009).

\subsection{Total energy use}

In the analysis reported in Section 4.1, the improvement in energy efficiency operates in a manner that is observationally equivalent to a change in the representative household's tastes, with fixed nominal income and prices. Whilest household utility will rise, the economic impact is reflected solely in consumption shifting. ${ }^{11}$ With rebound values less than $100 \%$ this implies a fall in consumption expenditure on energy and an increase in the expenditure on all other goods and services.

We can retain the partial equilibrium assumptions of fixed prices and household income but incorporate the impact on total energy use by adopting a Type I Input-Output analysis (Miller and Blair, 2009). In this approach, the impact on energy use in both household consumption

\footnotetext{
${ }^{10}$ We consider the estimated elasticity of energy demand as a proxy of the direct rebound effects (Khazzoom, 1980). This is the easiest and more straightforward definition of direct rebound, though it has been criticized by Sorrell and Dimitropoulos (2008) as subject to bias.

${ }^{11}$ The implications of this are dealt with in more detail in Section 6.2.
} 
and industrial production is identified and the relevant total rebound measure, as expressed in equation (2), can be calculated. This captures the notion of energy being embodied in consumption goods or services, in the form of the energy required, directly or indirectly, in the production of these goods and services.

We introduce a shock in the Input-Output system by reducing household final consumption expenditure on both UK and imported energy (coal, oil, gas and electricity). We simultaneously increase household spending on other (non-energy) goods and services, using the distribution of initial expenditure on domestic and imported non-energy goods and services given in the Input-Output accounts. This method shares some characteristics with Freire-Gonzalez (2011) and Thomas and Azevedo (2013a; 2013b) and extends Druckman et al. (2011) by incorporating the impact on indirect rebound from the reduction in energy use embodied in the reduction in domestic energy supply itself.

The change in household consumption expenditure on energy, $\Delta E_{C}$, is matched by an equal and opposite change in non-energy household expenditure, $\Delta N E_{C}$, and is given as:

$$
\Delta E_{C}=-\Delta N E_{C}=X_{T}\left(\frac{R_{C}}{100}-1\right) \lambda \gamma
$$

where $X_{T}$ is total household expenditure. Using Type I Input-Output multipliers, the change in total energy use, $\Delta \mathrm{E}_{\mathrm{T}}$, equals:

$$
\Delta E_{T}=\Delta E_{C}\left(1+m_{E}^{E}\right)+\Delta N E_{C} m_{N E}^{E}
$$

where $m_{E}^{E}$ and $m_{N E}^{E}$ are respectively the amounts of energy used domestically, directly or indirectly, in the production of one unit of energy and one unit of non-energy household consumption. Household energy use can be expressed either as the share, $\lambda$, of the total household expenditure or a share, $\alpha$, of the total energy use. Using this result produces: 


$$
E_{T}=\frac{\lambda X}{\alpha}
$$

Combining equations (10), (11) and (12) produces:

$$
\dot{E}_{T}=\alpha \gamma\left(\frac{R_{C}}{100}-1\right)\left(1+\Delta m^{E}\right)
$$

where $\Delta m^{E}=m_{E}^{E}-m_{N E}^{E}$. Substituting equation (13) into equation (2) gives:

$$
R_{T}=R_{C}\left(1+\Delta m^{E}\right)-100 \Delta m^{E}
$$

Equation (14) expresses the total partial equilibrium rebound, $\mathrm{R}_{\mathrm{T}}$, as a function of the rebound value in the household consumption of energy, $R_{C}$, and the difference between the embodied energy in the production of energy and non-energy goods and services, $\Delta m^{E}$. We expect the production of energy to be relatively energy intensive, so that $\Delta m^{E}>0$ : this is certainly the case in the UK Input-Output accounts. Combined with equation (14), this implies that the relationship between the partial equilibrium total and household consumption rebound is represented in Figure $1 .{ }^{12}$ As a benchmark, we also show in Figure 1 the locus of points where $\mathrm{R}_{\mathrm{C}}=\mathrm{R}_{\mathrm{T}}$.

It is clear from Figure 1 that where there is backfire in the household consumption of energy, so that $R_{C}>100 \%$, the partial equilibrium rebound value for total energy use is greater than the value for household energy consumption. However, where $\mathrm{R}_{\mathrm{C}}<100 \%$, the total rebound value is less than the corresponding household value. Further, there is a range of values for $\mathrm{R}_{\mathrm{C}}, 0 \leq R_{C}<\left[\frac{\Delta m^{E}}{1+\Delta m^{E}}\right] 100$, for which the total partial equilibrium rebound value is negative.

\footnotetext{
${ }^{12}$ In equation (14) the rebound effect incorporates all of the indirect effects, negative and positive. For an alternative approach see Guerra and Sancho (2010), where the embodied energy requirement of the energy supply sector is included as part of the potential direct energy savings.
} 
This means that the proportionate total energy reduction is greater than the efficiency improvement.

We can quantify the partial equilibrium total rebound generated by the consumption expenditure shifting associated with the improvement in household energy efficiency. Note that whilst we assume that the full adjustment of consumption expenditure to the change in household energy efficiency might take some time, the IO method for identifying energy use changes in production makes no such assumption. The passive supply implies that existing capacity already exists to meet any adjustments in demand.

For the $36.9 \%$ household consumption rebound value estimated using the short-run elasticity of substitution, the proportionate reduction in household consumer expenditure on energy, $\dot{E}_{C}$, equals $3.16 \%$. This corresponds to a $109355 \mathrm{TJ}$ reduction in household energy use and to a $£ 752.57$ million reallocation in UK household consumption across the seventeen non-energy consumption sectors. The result is a fall in total energy demand of $£ 1002$ million (137363 TJ) which corresponds to $1.44 \%$ of total UK energy use (across households and producers), so that $\dot{E}_{T}=-1.44 \%$. Given that $\gamma=5 \%$ and $\alpha$, the share of household consumption in total energy use, equals 0.344 , the total rebound value $\left(R_{T}\right)$ takes a value of $16.0 \%$. The indirect component of the rebound effect is therefore negative with a value of $20.9 \%{ }^{13}$

Where the estimated long-run demand elasticity is used in the rebound calculations, there is a larger household consumption rebound value. This implies a smaller reallocation of household expenditure in favour of non-energy goods and services. In this case, $\dot{E}_{C}$ indicates a $0.87 \%$ fall in expenditure on energy, a reduction of 65509 TJ which equates to $£ 450.9$ million to be reallocated to non-energy household consumption. The total energy rebound, $R_{T}$,

\footnotetext{
${ }^{13}$ From the figures presented in Table $3, \Delta \mathrm{m}^{\mathrm{E}}$ is 0.33 and the total rebound value is negative where $\mathrm{R}_{\mathrm{C}}<24.8 \%$.
} 
is $49.7 \%$, with the impact of indirect expenditures, $R_{T}-R_{C}$, being to reduce the rebound by 12.54 percentage points. These figures for the partial equilibrium total rebound are entered into the first row of Table 3.

Generally, there is an expectation that the total rebound will be bigger than the household consumption value. However, as we have seen, this does not hold in partial equilibrium if household rebound is less than $100 \%$. The indirect component of the rebound in this case is negative, putting downward pressure on the total rebound value. This effect will persist in a general equilibrium approach, as long as the balance of consumer expenditure moves towards non-energy commodities. However, the magnitude of this negative rebound component, being driven by changes in the demand for intermediate inputs, will be influenced by endogenous price, income and supply responses. For example, as demand for energy falls in the short run as a result of the pure efficiency effect, the market price may decrease, stimulating the derived demand for energy use in production. Similarly, the output of all commodities will be affected through changes in competitiveness, further influencing the demand for energy as an intermediate input. Finally, changes in domestic prices also impact the revenues of domestic producers, leading to adjustments in capacity in the general equilibrium setting to which we now turn our attention.

\section{General equilibrium rebound effects - endogenous prices and incomes}

The analysis in Section 4 holds prices and nominal household income fixed. In the analysis in this section, we allow prices and incomes to vary in determining the rebound effect. These effects are captured through the use of Computable General Equilibrium (CGE) modelling. To identify the general equilibrium impacts, we use a variant of the UKENVI CGE modelling framework. This is an energy-economy-environment version of the basic AMOS CGE model, 
calibrated on a UK Social Accounting Matrix (SAM) (Allan et al. 2007; Harrigan et al. 1991 and Turner, 2009). ${ }^{14}$ The core of the 2004 SAM is the 21 sector Input-Output table used in Section 4. This is augmented with information on income transfers between aggregate agents. These comprise the UK household, government and corporate sectors, plus two external transactors, the rest of the UK (RUK) and the rest of the world (ROW). We introduce a capital account that balances income and expenditures through which all capital formation is funded, and two factor accounts for incomes from capital and labour where incomes are initially channelled through the domestic agent accounts. Additional data used in the construction of the SAM are drawn mainly from National Statistics (2004).

Simulations performed under Scenario 1 use the standard model, UKENVI, as employed in Allan et al. (2007) and Turner (2009), augmented so that consumption and investment decisions reflect inter-temporal optimization with perfect foresight (Lecca et al. 2013a). The model is outlined in more detail in Appendix A and the full mathematical presentation of the model can be found in the supplementary material accompanying this paper.

Under Scenario 2, the increased energy efficiency in household consumption is directly reflected in real wage determination, given in equation (A.3) in Appendix A. This involves modifying the consumer price index $(c p i)$ so that the price of energy services is expressed in efficiency units. . We can incorporate the efficiency change in the wage bargaining process by simply adjusting the cpi by measuring the price of energy in efficiency units:

$$
p_{E}^{F}=\frac{p_{E}}{1+\gamma}<p_{E} \quad \text { for } \gamma>0
$$

so that

\footnotetext{
${ }^{14}$ AMOS is an acronym for A micro-macro Model Of Scotland. Whilst AMOS was initially calibrated on Scottish data, its flexible framework incorporates a wide range of possible model configurations which can be calibrated to data for any small open regional or national economy.
} 


$$
c p i_{\tau}=\operatorname{cpi}\left(p_{N E}, p_{E}^{F}\right)
$$

where $p_{N E}$ is the price of non-energy goods and services, and $p_{E}$ and $p_{E}^{F}$ are the price of energy measured in natural and efficiency units. This means that with constant energy prices in natural units, $p_{E}$, an improvement in energy efficiency reduces the price of energy in terms of efficiency units, $p_{E}^{F}$. In this scenario, this reduces the $c p i$ which has a direct effect on the nominal wage rate.

The model calibration process assumes the economy to be initially in steady state equilibrium. As in the partial equilibrium simulations, we introduce a costless and permanent $5 \%$ step increase in the efficiency with which energy is used in household consumption. We report results for two conceptual time periods, the short and the long run, together with period-byperiod impacts for some simulations. The short run corresponds to the first period of the simulation, where the capital stock is fixed, both in its total and its sectoral composition, at the base period values. However, from period two onwards, capital stock adjusts through investment and depreciation. In the long run, the state variables of the model are subject to transversality conditions, so as to obtain a new steady-state.

As discussed in Section 3, when the analysis applies to the long run, we always use the longrun elasticity of substitution. However, in the short run, we perform simulations using both the short-run and long-run substitution elasticities. Recall that the long-run elasticity values might be more appropriate, even in short-run simulations, if energy efficiency is embodied in the design of consumer durables.

Table 4 shows the short and long-run impact of the improved household energy efficiency on key macroeconomic variables using the conventional perfect foresight UKENVI model. We 
label this Scenario 1. We report the results as percentage changes from the base year values. In Scenario 2, the model is adjusted, as shown in in equation (15) and (16), so that the cpi incorporates the price of energy in efficiency, rather than natural, units. The results from this simulation are reported in Table 5.

\subsection{Scenario 1: The standard model}

The Scenario 1 results are given in Table 4. In the short run, simulations using the short-run elasticity of substitution report a $2.64 \%$ reduction in household energy consumption. The switch in household expenditure towards non-energy consumption has a small expansionary impact on the economy: total output, consumption and investment increase by $0.04 \%, 0.22 \%$ and $0.14 \%$ respectively. ${ }^{15}$ There is a corresponding stimulus to labour demand, lowering the unemployment rate by $0.23 \%$ and increasing the real wage by $0.03 \%$.

The fall in energy demand from households is accompanied by a $0.24 \%$ fall from industry because of the relative energy intensity of the production of energy itself. This is the same source of negative total rebound pressure identified in Section 4. Total energy use and output fall by $1.07 \%$ and $0.87 \%$ respectively. However, energy prices are now endogenous and fall in the short run, shown in Figure 2. This means that the decline in domestic energy use is partly offset by some substitution towards energy in production and changes in output driven by adjustments in exports and import substitution. The short-run increase in exports produced by the increase in competitiveness is illustrated in Figure 3. These price reductions are caused by the short-run emergence of overcapacity in those sectors following the efficiency improvement.

\footnotetext{
${ }^{15}$ The household consumption value is the change in real household consumption. This implies that the increase in efficiency in the household use of energy would register as a stimulus to real consumption, even if the nominal household income and prices were held constant.
} 
The second column of Table 4 reports the short-run impacts where the long-run elasticity of substitution between energy and non-energy goods and services is imposed. Note that in this case there is a smaller reduction in household consumption of energy of $1.42 \%$. This means that there is less expenditure switching, which has two general implications. The first is that the expansionary impacts, whilst still present, are all slightly smaller than where the short-run elasticity is used. This is because non-energy expenditure has a greater impact on the UK economy than the same amount of expenditure on energy. The second is that the total reduction in energy use is also lower, at $0.57 \%$.

In the long-run results, shown in the third column in Table 4, household consumption of energy, energy demand by industry, total energy use and total energy output all remain below their base-year values. However, there is a $0.10 \%$ increase in GDP and similar increases in total employment and investment. The expansion in the long run is greater than in the short run as the ability to adjust capacity allows a greater response to the net positive demand stimulus. Because the labour force is assumed to be fixed, there is a fall in the unemployment rate generating an increase in the real wage which, in turn, puts upward pressure on all commodity prices and reduces competitiveness. This is shown in Figures 2 and 4.

Figure 4 reports the percentage change in sector prices relative to the base year level for the whole period of adjustment, using the long-run elasticity of substitution value in each time period. The demand shock generates short-run shifts in prices which reflect the change in household demand. There are short-run price reductions in coal, gas and electricity but corresponding price increases in all other sectors. Over time, the adjustment of capacity leads to small increases in prices in all sectors. The long-run price behaviour differs from that generally obtained where the energy efficiency improvement applies to the production side of 
the economy. For improvements in energy efficiency in production, economic activity is stimulated through downward pressure on prices. This includes the price of energy output itself since the energy supply sector is typically energy intensive.

While the increase in total investment in Scenario 1 means that there is an increase in capital stock over time in non-energy sectors, decreased output leads to a contraction in capacity in energy sectors. The trigger for this disinvestment is the fall in the shadow price of capital caused by the initial contraction in demand for energy sector outputs. Energy firms' profit expectations therefore fall. This is reflected in Figure 5, where we plot the shadow price of capital and the replacement cost of capital for the energy sectors. In each of these sectors, the shadow price of capital is below the replacement cost of capital over the entire adjustment path, implying that Tobin's $\mathrm{q}<1$ in these sectors. Ultimately, there is complete adjustment where the capital stock reaches the steady-state equilibrium. After the initial fall, the price of energy rises over time, allowing the shadow price of capital to converge on the replacement cost of capital, so that Tobin's q asymptotically approaches unity.

Again, using equations (1) and (2) and the household and total energy change figures identified in this section we can calculate the household and total energy rebound effects. These are reported in rows 2 and 3 of Table 3. In the short-run simulations the rebound values for household energy use are $47.3 \%$, using the short-run elasticity of substitution, and $71.6 \%$ for the long-run value. The corresponding short-run general equilibrium total rebound values using the short- and long-run substitution elasticities are $38.5 \%$ and $67.1 \%$ respectively. For the long-run values, which always use the long-run substitution elasticity, the household and total rebound values are $67.6 \%$ and $59.3 \%$.

\subsection{Scenario 2: Measuring energy prices in efficiency units for the consumer price index}


In Scenario 1, the increase in energy efficiency in the household sector acts in a way that is observationally equivalent to a change in tastes. This is because, as shown in equation (14), in the calculation of the real wage the consumer price index, cpi, combines the price of nonenergy and energy commodities measured in natural units. However, it might be more appropriate in defining the $c p i$ to measure the composite energy price in efficiency units. This implies that the cpi should be calculated as in equations (15) and (16). With this approach, in so far as improvements in energy efficiency reduce the energy price (measured in efficiency units), this will be translated into a fall in the cpi, which will put downward pressure on the nominal wage and serve as a source of improved competitiveness.

Scenario 2 repeats the simulation of a 5\% step increase in energy efficiency in household consumption. All aspects of the simulations are exactly the same as those reported for Scenario 1 in Section 5.1, apart from the difference in the calculation of the cpi. The percentage changes in key economic variables are reported in Table 5 and the corresponding rebound values in Table 6 . The changes in the prices for individual commodities over time are given in Figure 6.

In the standard case reported as Scenario 1, both the cpi and the nominal wage rise and are maintained above their base year values in the long run. However, in Scenario 2, these results are reversed. In the short run, both the short or long-run substitution elasticity simulations produce a fall in the nominal wage of $0.13 \%$ and $0.12 \%$ respectively. The fall in the nominal wage in the long run is $0.11 \%$. As shown in Figure 6, this reduction in labour costs generates a fall in the price of output in all production sectors. The resulting stimulus to competitiveness has an expansionary effect that offsets the impact on aggregate demand of a lower nominal wage. Thus Scenario 2 exhibits a much larger stimulus to GDP, employment and investment 
than Scenario 1. All these aggregate activity variables increase in the long run by around $0.25 \%$.

The reduction in energy use is always bigger in Simulation 1 than in the corresponding result under Simulation 2. That is to say, the bigger stimulus to the economy under Simulation 2 reduces the energy saving. However, the additional impact on energy use and the associate rebound effects are small. Even in the long run, where the relative expansionary effect of the increased energy efficiency is greatest, the total energy rebound for Scenario 2 is $54.3 \%$, against the Scenario 1 figure of $48.5 \%$.

\section{The added value from a general equilibrium analysis}

In comparing the general and partial equilibrium analysis, and therefore the added value from a general equilibrium approach, we begin by considering the rebound values for the simulations in Scenario 1, reported in Table 3. These results reveal that the same basic data can generate a wide range of possible rebound figures, which depend upon the narrowness of the focus of the analysis, the value of key parameters, the time scale and whether a partial or general equilibrium approach is adopted.

The first row in Table 3 gives the partial equilibrium values. Recall that these apply to the rebound on an individual household's energy consumption if that household alone experienced the improved energy efficiency, with money income and energy prices unchanged. First, focus on the household energy rebound, which solely concerns the direct energy use by households. Clearly general equilibrium effects are not required in order to get substantial rebound values. Moreover, comparing the results with short and long-run values, the larger the elasticity of substitution between energy and non-energy in household 
consumption, that is, the more flexible consumption is in accommodating the efficiency gains, the greater the rebound will be. Second, the total rebound values are less than the household consumption values. This reflects the shift of household expenditure away from the intermediate demand energy intensive energy sectors towards less energy intensive commodities and services, as argued in Section 4.2. Moreover, the difference between the total and household consumption rebound values narrows as the household consumption value increases, as shown in Figure 1.

A general equilibrium analysis involves incorporating the effect on energy use of endogenous changes in prices, wages and incomes. Consider first the short-run Scenario 1 values given in row two in Table 3. The effect of the change in household income and prices over this time interval increases the household rebound values by around 10 percentage points. The increase is slightly greater when using the short-, as against long-run substitution elasticity. Household income increases in real term by around $0.06 \%$ for both short- and long-run substitution elasticities. For an income elasticity equal to one, as imposed in this model, we should expect a similar percentage increase in household energy consumption (although the linearity assumption between income and consumption does not strictly hold here given the perfect foresight of households). As a result, in these simulations changes in endogenous household income increase the general equilibrium rebound values by around 1.2 percentage points. The relative price changes, shown in Figure 4, generate the remaining, larger, household rebound effects of around 9 percentage points. The short run significant falls in energy prices in natural units, as a result of temporary excess capacity, leads to the substitution of energy for other commodities in the household budget.

For total energy use, the gap between the partial and general equilibrium short-run rebound values is greater. The short-run total energy rebound figures are around 20 percentage points 
higher under general equilibrium than partial equilibrium. Again the additional rebound is slightly bigger for the short-run substitution elasticities. The difference between the partial and general equilibrium total rebound values include changes already identified as contributing to household rebound. These stand at just over 10 percentage points. However, there are three additional factors operating on total energy use in general equilibrium and they all increase the total rebound figure.

First, the negative impact on rebound through the different energy intensities of the intermediate inputs in energy and non-energy sectors is reduced following the increased rebound in household consumption as indicated in Figure 1. This makes up 3 percentage points. The remaining 7 percentage point difference comes from additional relative price effects on intermediate energy demand. These comprise the substitution of energy for nonenergy commodities as intermediate inputs together with the fall in exports and increased import penetration in non-energy sectors, and the rising exports and import substitution in energy sectors. The difference between the general and partial equilibrium short-run total energy rebound values is therefore driven primarily by endogenous relative price, rather than income, effects.

The long-run general equilibrium rebound figures for Scenario 1 are shown in row 3 of Table 4. For both the household and total energy rebound, the long-run general equilibrium value lies between the corresponding partial equilibrium and short-run general equilibrium figures. The long-run general equilibrium simulations generate larger positive changes in household income and GDP than the partial equilibrium or short-run general equilibrium values. ${ }^{16}$ However, over the long run, capacity adjustments reduce the changes in commodity prices,

\footnotetext{
${ }^{16}$ Change in real income is around $0.10 \%$ from base year value. Generally the long-run change in income should equate with the change in consumption. However, given that the increase in consumption is partly due to an increase in efficiency, the total change in consumption is higher than the change in current income and total household wealth.
} 
which are ultimately only driven by the impact of the higher nominal wage across different sectors. This means that the substitution and competitiveness effects that increase the rebound effects under short-run general equilibrium are much reduced in the long run. However, a key point to note is that there is a mix of positive and negative pressure impacting the general equilibrium rebound results in both the short-run and the long-run.

In Scenario 2, the improvement in household efficiency in the use of energy is allowed to feed through to increased competitiveness via downward pressure on the nominal wage. The short and long-run general equilibrium rebound results are given in Table 6. Comparing these figures with the corresponding rebound values reported in Table 3 gives the following results.

The incorporation of this additional general equilibrium effect has almost no impact on the household energy use rebound values in either the short or long run. That is to say, the household rebound results shown in Table 6 are very similar to the corresponding values in Table 4. Whilst employment is higher in the simulations under Scenario 2, the nominal wage is lower so this has an offsetting effect on energy consumption. Also energy production is relatively capital intensive so that the price of energy will generally rise against other household consumption, which will tend to reduce energy consumption. Also in the model a number of transfers are fixed in real terms, so that when the cpi falls the nominal value of these transfers also falls.

However, the Scenario 2 total energy use rebound values are always higher than their Scenario 1 counterparts. The greater expansion of GDP under Scenario 2, together with the fact that the efficiency of energy use in production has not been increased, generates this result. However, the differences are quite modest, the largest being for the long-run rebound value which increases by 4.6 percentage points to $63.9 \%$ in Scenario 2 . 


\section{Conclusions}

The main contribution of this paper is to investigate the impact of efficiency improvement in the use of energy in household consumption and show the resulting partial and general equilibrium household and total energy rebound values. The results, summarised in Tables 3 and 6, serve both a practical and conceptual purpose. They indicate the range of rebound values that can be derived from a given basic data set, depending on the precise way that the rebound measure is specified. However, these results also show how the rebound values can be deconstructed to reveal the relative size of the various effects.

Let us begin with partial equilibrium. First, note that the value of the elasticity of substitution between energy and non-energy commodities in household consumption is important in determining the size of this effect. This finding reflects observations made in the case of increased efficiency in productive energy use by several authors (including Saunders, 1992; Sorrell, 2007; Turner, 2009) but extends to the case of household energy efficiency. We find that the appropriate elasticity value depends not only on the time period under consideration but also whether the efficiency improvement is embedded in the design of household durable goods or not. Second, we strongly identify the negative impact on the rebound value when the focus shifts from household consumption to total energy consumption. This phenomenon reflects the relative energy intensity of energy production itself. This means that when direct household consumption of energy falls, indirect consumption of energy falls also, reducing the total rebound. Moreover, we demonstrate that this negative pressure on rebound is present in both partial and general equilibrium cases, though it may be partially offset through price effects in the latter. 
The substitution elasticity and intermediate input effects identified under partial equilibrium remain largely undiminished in the general equilibrium analysis. However, general equilibrium also incorporates the impact of changes in relative prices, incomes and economic activity. We observe that the main additional general equilibrium impacts occur in the short run where the fall in energy prices cushions the fall in energy use. This leads to the short-run general equilibrium rebound values being greater than both the corresponding partial equilibrium and long-run general equilibrium figures (for the same elasticity of substitution value). In the long run, capital adjustments severely reduce the relative price changes that occur in the short run, leaving the rebound values closer to their partial equilibrium counterparts. Finally, where further expansionary effects of the energy efficiency improvement are incorporated through a fall in the nominal wage, the positive additional rebound effect is relatively limited.

Our findings have important implications for the consideration of policies aimed at increasing energy efficiency in the household sector. First, the nature of the general equilibrium response under these circumstances is quite different to that where efficiency improves in production. However, existing analyses by, for example, the IEA have focussed on the relationship between economy-wide rebound and productivity-led growth (Ryan and Campbell, 2012). We have shown here that the transmission mechanism that links energy efficiency improvements on the consumption side of the economy with energy use in the production side operates through changing derived demand and prices, with no change in productivity in production. Only where the efficiency improvement directly impacts wage demands does industry enjoy a reduction in factor input prices.

The second key feature of interest to policy analysts is the need to understand the general equilibrium dynamics that put a range of upward and downward pressures on economy-wide 
rebound at different stages of the adjustment process. To date much of the policy (and academic) literature on the issue of rebound has focussed on the range of demand-side drivers of rebound with insufficient attention to the capacity and pricing decisions of energy suppliers when they are faced with changing demand for, and revenues from, their production. 


\section{References}

Allan, G., Hanley, N., McGregor, P., Swales, J.K., Turner, K., (2007). "The impact of increased efficiency in the industrial use of energy: a computable general equilibrium analysis for the United Kingdom”, Energy Economics, vol. 29, pp. 779-798.

Armington, P. (1969). "A theory of demand for products distinguished by place of production", IMF Staff Papers, vol. 16, 157-178.

Baker, P. and Blundell R., (1991). "The microeconometric approach to modelling energy demand: some results for UK households", Oxford Review of Economic Policy, vol. 7, pp. 5476.

Baker, P., Blundell, R., and Micklewright, J. (1989). "Modelling household energy expenditures using micro-data", Economic Journal, vol. 99, no. 397, pp. 720-738.

Dimitropoulos, J., (2007). "Energy productivity improvements and the rebound effect: an overview of the state of knowledge", Energy Policy, vol. 35, N.12, pp. 6354-6363.

Druckman, A., Chitnis, M., Sorrell, S. and Jackson, T. (2011). "Missing carbon reductions? Exploring rebound and backfire effects in UK households", Energy Policy, MORE UP TO DATEin press, doi.10.1016/j.enpol.2011.03.058.

Dubin, J.A., Miedema, A.K., Chandran, R.V., (1986). "Price effects of energy-efficient technologies: a study of residential demand for heating and cooling", Rand Journal of Economics, vol. 17, no. 3, pp. 310-325.

Dufournaud, C.M., Quinn, J.T., Harrington, J.J., (1994). “An applied general equilibrium (AGE) analysis of a policy designed to reduce the household consumption of wood in the Sudan", Resource and Energy Economics, vol. 16, no. 1, pp. 69-90.

Evans, D.J., 2005. "The Elasticity of Marginal Utility of Consumption: Estimates for 20 OECD Countries", Fiscal Studies, vol. 26, No. 2, pp. 197-224.

Fouquet, R. (2012) "Trends in income and price elasticities of transport demand (18502010)", Energy Policy (Special Issue on Past and Prospective Energy Transitions), vol. 50: pp. 62-71.

Fouquet, R. and Pearson P. J.G. (2012) "The long run demand for lighting: elasticities and rebound effects in different phases of economic development", Economics of Energy and Environmental Policy, vol. 1, no. 1, pp. 83-100.

Freire-Gonzalez, J., (2010). "Empirical evidence of direct rebound effects in Catalinia", Energy Policy, vol. 38, no. 5, pp. 2309-2314.

Freire-Gonzalez, J., (2011). "Methods to empirically estimate direct and indirect rebound effect of energy-saving technological changes in households", Ecological Modelling, vol. 223, no. 1, pp.32-40.

Frondel M, Peters J., and Vance C., (2008). "Identifying the rebound: evidence from a German household panel", The Energy Journal, vol. 29, no. 4, pp. 145-163. 
Gibson, H., (1990). "Export competitiveness and UK sales of Scottish manufacturers", Working paper, Scottish Enterprise. Glasgow, Scotland.

Golan A., Judge G. and Miller D., (1996). Maximum entropy econometrics: robust estimation with limited data, John Wiley \& Sons: New York.

Gørtz, E., (1977). "An identity between price elasticities and the elasticity of substitution of the utility function", The Scandinavian Journal of Economics, vol. 79, no. 4, pp. 497-499.

Greene, D.L., Kahn, J.R., Gibson, R.C., (1999). "Fuel economy rebound effect for U.S. household vehicles", The Energy Journal, vol. 20, no. 3, pp. 1-31.

Greening, L.A., Greene, D.L., Difiglio, C., (2000). "Energy efficiency and consumption - the rebound effect - a survey”, Energy Policy, vol. 28, no. 6-7, pp.389-401.

Guerra, A. I. and Sancho, F., (2010). Rethinking economy-wide rebound measures: an unbiased proposal", Energy Policy, vol. 38, no. 11, pp. 6684-6694.

Harrigan, F., McGregor P., Perman R., Swales K. and Yin Y., (1991). "AMOS: A macromicro model of Scotland”, Economic Modelling, vol. 8, no. 4, pp. 424-479.

Harris, R., (1989). The growth and structure of the UK regional economy, 1963-1985. Aldershot: Avebury.

Khazzoom, J.D., (1980). "Economic implications of mandated efficiency in standards for household appliances", Energy Journal, vol. 1, no.4, pp. 21-40.

Khazzoom, J.D., (1987). "Energy savings from the adoption of more efficient appliances", Energy Journal, vol. 8, no. 4, pp. 85-89.

Klein, Y.L., (1985). "Residential energy conservation choices of poor households during a period of rising energy prices", Resources and Energy, vol. 9, no. 4, pp. 363-378.

Klein, Y.L., (1987). "An econometric model of the joint production and consumption of residential space heat", Southern Economic Journal, vol. 55, No. 2, pp. 351-359.

Layard R., Nickell S., Jackman R., 1991. Unemployment: Macroeconomic Performance and the Labour Market. Oxford University Press, Oxford.

Lecca P., McGregor, P.G. and Swales J.K. (2013a). "Forward-looking and myopic regional Computable General Equilibrium models: How significant is the distinction?", Economic Modelling, vol. 3, no. 6, pp. 160-176

Lecca, P., Swales J.K., and Turner, K. (2011). Rebound effects from increased efficiency in the use of energy by UK households, Strathclyde Discussion Papers in Economics, 11-23.

Lecca, P., McGregor, P.G., Swales J.K. and Turner, K. (2013b). The added value from a general equilibrium analyses of increased efficiency in household energy use, Strathclyde Discussion Papers in Economics, 13-08.

Miller R.E. and Blair P.D, (2009). Input-Output Analysis. Foundation and Extension, Cambridge University Press, Cambridge. 
Nadel, S.M., (1993). The take-back effect: fact or fiction? Proceedings of the 1993 Energy Program Evaluation Conference, Chicago, Illinois, pp. 556-566.

National Statistics (2004). "United Kingdom National Accounts: The Blue Book", edited by Paul Culllinane. The Stationary Office, London

Ryan, L. and Campbell, N. (2012) "Spreading the net: the multiple benefits of energy efficiency improvements", International Energy Agency Insights Series 2012. OECD/IEA, Paris

Saunders, H.D. (1992) "The Khazzoom-Brookes postulate and neoclassical growth", The Energy Journal, vol. 13, no. 4, pp. 131-148.

Schwartz, P.M. and Taylor, T.N., (1995)"Cold hands, warm hearth? Climate, net takeback, and household comfort", Energy Journal, vol. 16, no.1, pp. 41-54.

Sorrell, S. (Ed.) (2007) "The Rebound Effect: an assessment of the evidence for economywide energy savings from improved energy efficiency", UK Energy Research Centre. Available at:

http://www.ukerc.ac.uk/Downloads/PDF/07/0710ReboundEffect/0710ReboundEffectReport.p df.

Sorrell, S. and Dimitropoulos, J., (2008). "The rebound effect: microeconomic definitions, limitations and extensions", Ecological Economics, vol. 65, no. 3, pp.636-649.

Sorrell, S., Dimitropoulos, J., and Sommerville, M., (2009). "Empirical estimates of the direct rebound effect: A review”, Energy Policy, vol. 37, no.13, pp. 1356-1371.

Thomas, B.A., and Azevedo, I.L., (2013a) "Estimating direct and indirect rebound effects for U.S. households with input-output analysis Part 2: Simulation", Ecological Economics, vol. 86, pp.188-198.

Thomas, B.A. and Azevedo, I.L. (2013b) "Estimating direct and indirect rebound effects for U.S. households with input-output analysis Part 1: Theoretical Framework", Ecological Economics, vol. 86, pp. 199-210.

Turner, K., (2009). Negative rebound and disinvestment effects in response to an improvement in energy efficiency in the UK economy, Energy Economics, vol. 31, no.5, pp. 648-666.

Turner, K. (2013), "Rebound effects from increased energy efficiency: a time to pause and reflect?", The Energy Journal, vol. 34, no. 4, pp.25-42

West, S. E., (2004). "Distributional effects of alternative vehicle pollution control policies", Journal of Public Economics, vol. 88, no. 3-4, pp. 735-757. 
Table 1: The indusustrial disaggregation for the UKENVI 21-sector model

\begin{tabular}{|c|c|}
\hline & $\begin{array}{l}\text { Original sector numbers from the } 123 \\
\text { UK IO table }\end{array}$ \\
\hline Agriculture, forestry and logging & $1+2$ \\
\hline Sea fishing and fish farming & 3 \\
\hline Mining and extraction & $5+6+7$ \\
\hline Food, drink and tobacco & $8-20$ \\
\hline Textiles and clothing & $21-30$ \\
\hline Chemicals etc & $36-53$ \\
\hline Metal and non-metal goods & $54-61$ \\
\hline $\begin{array}{l}\text { Transport and other machinery, electrical and } \\
\text { instrument engineering }\end{array}$ & $62-80$ \\
\hline Other manufacturing & $31-34+81-84$ \\
\hline Water & 87 \\
\hline Construction & 88 \\
\hline Distribution & $89-92$ \\
\hline Transport & $93-97$ \\
\hline Communications, finance and business & $98-107+109-114$ \\
\hline R\&D & 108 \\
\hline Education & 116 \\
\hline Public and other services & $115+117-123$ \\
\hline Coal extraction & 4 \\
\hline Oil (refining and distribution) and nuclear & 35 \\
\hline Gas & 86 \\
\hline Electricity & 85 \\
\hline
\end{tabular}


Table 2: The UK direct and Type I energy coefficients, 2004

\begin{tabular}{|c|c|c|c|c|c|c|c|c|}
\hline & \multicolumn{4}{|c|}{$\begin{array}{l}\text { Direct input-output } \\
\text { coefficients }\end{array}$} & \multicolumn{4}{|c|}{$\begin{array}{c}\text { Type I embodied energy } \\
\text { multipliers }\end{array}$} \\
\hline & లే & $\overline{0}$ & $\tilde{J}_{0}^{\mathscr{Z}}$ & 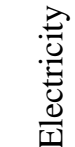 & ठี & $\overline{0}$ & $\tilde{J}_{0}^{n}$ & $\begin{array}{l}\stackrel{\overrightarrow{0}}{0} \cdot \frac{0}{0} \\
\frac{0}{0} \\
\frac{0}{I}\end{array}$ \\
\hline Agriculture, forestry and logging & 0.00 & 0.02 & 0.00 & 0.01 & 0.00 & 0.02 & 0.01 & 0.02 \\
\hline Sea fishing and sea firming & 0.00 & 0.09 & 0.02 & 0.04 & 0.00 & 0.11 & 0.03 & 0.07 \\
\hline Mining and extraction & 0.00 & 0.00 & 0.01 & 0.01 & 0.00 & 0.01 & 0.01 & 0.02 \\
\hline Food, drink and tobacco & 0.00 & 0.00 & 0.01 & 0.01 & 0.00 & 0.01 & 0.01 & 0.03 \\
\hline Textiles and clothing & 0.00 & 0.00 & 0.01 & 0.01 & 0.00 & 0.01 & 0.01 & 0.03 \\
\hline Chemicals etc & 0.00 & 0.00 & 0.01 & 0.02 & 0.00 & 0.01 & 0.02 & 0.05 \\
\hline Metal and non-metal goods & 0.00 & 0.01 & 0.01 & 0.02 & 0.00 & 0.01 & 0.02 & 0.06 \\
\hline Transport and other machinery, electrical and inst eng & 0.00 & 0.00 & 0.00 & 0.01 & 0.00 & 0.01 & 0.01 & 0.03 \\
\hline Other manufacturing & 0.00 & 0.00 & 0.01 & 0.01 & 0.00 & 0.01 & 0.01 & 0.03 \\
\hline Water & 0.00 & 0.00 & 0.00 & 0.02 & 0.00 & 0.00 & 0.01 & 0.03 \\
\hline Construction & 0.00 & 0.00 & 0.00 & 0.00 & 0.00 & 0.01 & 0.00 & 0.01 \\
\hline Distribution & 0.00 & 0.01 & 0.00 & 0.01 & 0.00 & 0.01 & 0.00 & 0.02 \\
\hline Transport & 0.00 & 0.04 & 0.00 & 0.00 & 0.00 & 0.05 & 0.00 & 0.02 \\
\hline Communications, finance and business & 0.00 & 0.00 & 0.00 & 0.00 & 0.00 & 0.01 & 0.00 & 0.01 \\
\hline$R \& D$ & 0.00 & 0.00 & 0.00 & 0.01 & 0.00 & 0.01 & 0.00 & 0.02 \\
\hline Education & 0.00 & 0.00 & 0.00 & 0.01 & 0.00 & 0.01 & 0.00 & 0.01 \\
\hline Public and other services & 0.00 & 0.00 & 0.00 & 0.00 & 0.00 & 0.01 & 0.01 & 0.02 \\
\hline Coal & 0.05 & 0.02 & 0.01 & 0.04 & 1.06 & 0.03 & 0.02 & 0.07 \\
\hline Oil & 0.00 & 0.02 & 0.00 & 0.01 & 0.00 & 1.02 & 0.01 & 0.03 \\
\hline Gas & 0.00 & 0.01 & 0.09 & 0.15 & 0.01 & 0.01 & 1.12 & 0.24 \\
\hline Electricity & 0.05 & 0.01 & 0.07 & 0.28 & 0.07 & 0.02 & 0.11 & 1.42 \\
\hline
\end{tabular}


Table $3^{*}$ : Partial and general equilibrium energy rebound values for the standard

UKENVI model

Scenario 1

\begin{tabular}{|l|l|l|l|l|}
\hline \multirow{2}{*}{} & \multicolumn{3}{c|}{$\varepsilon_{S R}$} & \multicolumn{2}{c|}{$\varepsilon_{L R}$} \\
\cline { 2 - 5 } & Household & Total & Household & Total \\
\hline Partial Equilibrium. & 36.9 & 16.0 & 62.2 & 49.7 \\
\hline Short-Run General Equilibrium & 47.3 & 38.1 & 71.6 & 67.1 \\
\hline Long-Run General Equilibrium & - & - & 67.6 & 59.3 \\
\hline
\end{tabular}

${ }^{*} \varepsilon_{S R}, \varepsilon_{L R}$ are the short and long-run substitution elasticities in consumption.

Table 4*: The short-run and long-run \% change in key economic variables resulting from a $5 \%$ increase in household energy efficiency for the standard UKENVI model

\section{Scenario 1}

\begin{tabular}{|l|r|r|r|}
\hline \multicolumn{1}{|c|}{ Elasticity of substitution } & \multicolumn{1}{|c|}{$\varepsilon_{S R}$} & $\varepsilon_{L R}$ & \multicolumn{1}{c|}{$\varepsilon_{L R}$} \\
\hline Time period & \multicolumn{2}{|c|}{ Short-run } & Long-run \\
\hline GDP & 0.04 & 0.03 & 0.10 \\
Consumer Price Index & 0.06 & 0.06 & 0.03 \\
Unemployment Rate & -0.23 & -0.18 & -0.40 \\
Total Employment & 0.06 & 0.05 & 0.10 \\
Nominal Gross Wage & 0.09 & 0.08 & 0.07 \\
Real Gross Wage & 0.03 & 0.02 & 0.04 \\
Households Consumption & 0.22 & 0.20 & 0.25 \\
Investment & 0.14 & 0.16 & 0.10 \\
Export & -0.08 & -0.08 & -0.04 \\
Non-Energy Output & 0.07 & 0.05 & 0.12 \\
Energy output & -0.87 & -0.47 & -0.61 \\
Energy Use & -1.07 & -0.57 & -0.70 \\
Energy Demand by Industries & -0.24 & -0.12 & -0.22 \\
Household Consumption of Energy & -2.64 & -1.42 & -1.62 \\
\hline
\end{tabular}

${ }^{*} \varepsilon_{S R}, \varepsilon_{L R}$ are the short and long-run substitution elasticities in consumption. 
Table $5^{*}$ :The short-run and long-run \% change in key economic variables resulting from a 5\% increase in household energy efficiency for the adjusted UKENVI model

\section{Scenario 2}

\begin{tabular}{|l|r|r|r|}
\hline \multicolumn{1}{|c|}{ Elasticity of substitution } & \multicolumn{1}{|c|}{$\varepsilon_{S R}$} & \multicolumn{1}{c|}{$\varepsilon_{L R}$} & \multicolumn{1}{c|}{$\varepsilon_{L R}$} \\
\hline Time period & \multicolumn{2}{|c|}{ Short-run } & Long-run \\
\hline GDP & 0.10 & 0.09 & 0.24 \\
Consumer Price Index & -0.17 & -0.16 & -0.22 \\
Unemployment Rate & -0.65 & -0.59 & -0.99 \\
Total Employment & 0.16 & 0.15 & 0.25 \\
Nominal Gross Wage & -0.13 & -0.12 & -0.11 \\
Real Gross Wage & 0.04 & 0.04 & 0.11 \\
Households Consumption & 0.22 & 0.20 & 0.29 \\
Investment & 0.37 & 0.39 & 0.24 \\
Export & -0.02 & -0.02 & 0.06 \\
Non-Energy Output & 0.13 & 0.11 & 0.25 \\
Energy output & -0.83 & -0.43 & -0.52 \\
Energy Use & -1.04 & -0.54 & -0.62 \\
Energy Demand by Industries & -0.19 & -0.07 & -0.11 \\
Household Consumption of Energy & -2.64 & -1.43 & -1.59 \\
\hline
\end{tabular}

Table $6^{*}$ : General equilibrium energy rebound values for the adjusted UKENVI model Scenario 2

\begin{tabular}{|c|c|c|c|c|}
\hline & \multicolumn{2}{|c|}{$\varepsilon_{S R}$} & \multicolumn{2}{|c|}{$\varepsilon_{L R}$} \\
\hline & Household & Total & Household & Total \\
\hline Short-run & 47.2 & 39.8 & 71.4 & 68.7 \\
\hline Long-Run & & & 68.2 & 63.9 \\
\hline
\end{tabular}

${ }^{*} \varepsilon_{S R}, \varepsilon_{L R}$ are the short and long-run substitution elasticities in consumption. 


\section{FIGURES}

Figure 1: The relationship between the partial equilibrium household consumption rebound and total rebound

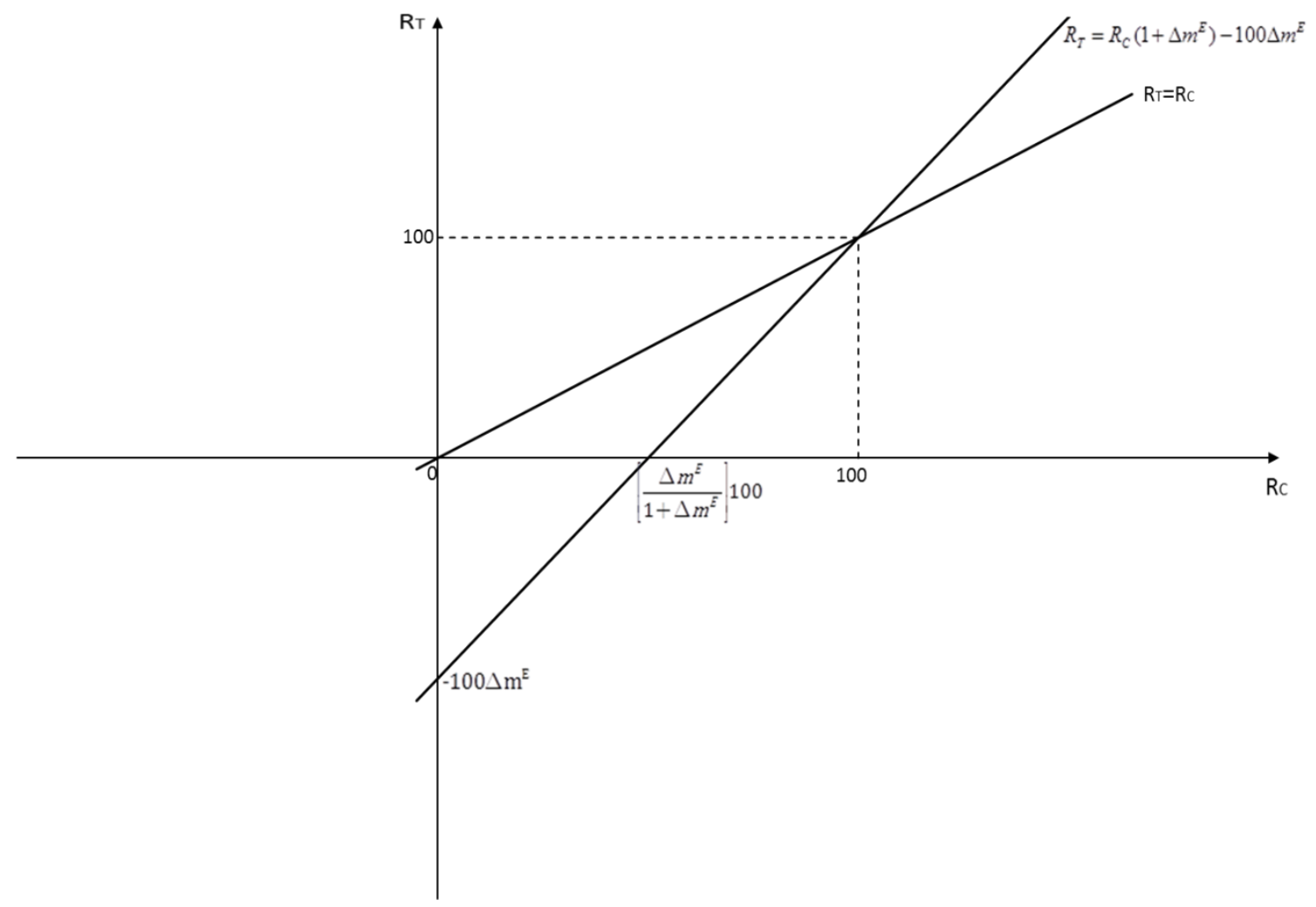


Figure $2^{*}$ : Percentage change in commodity prices with the standard UKENVI model.

\section{Scenario 1}

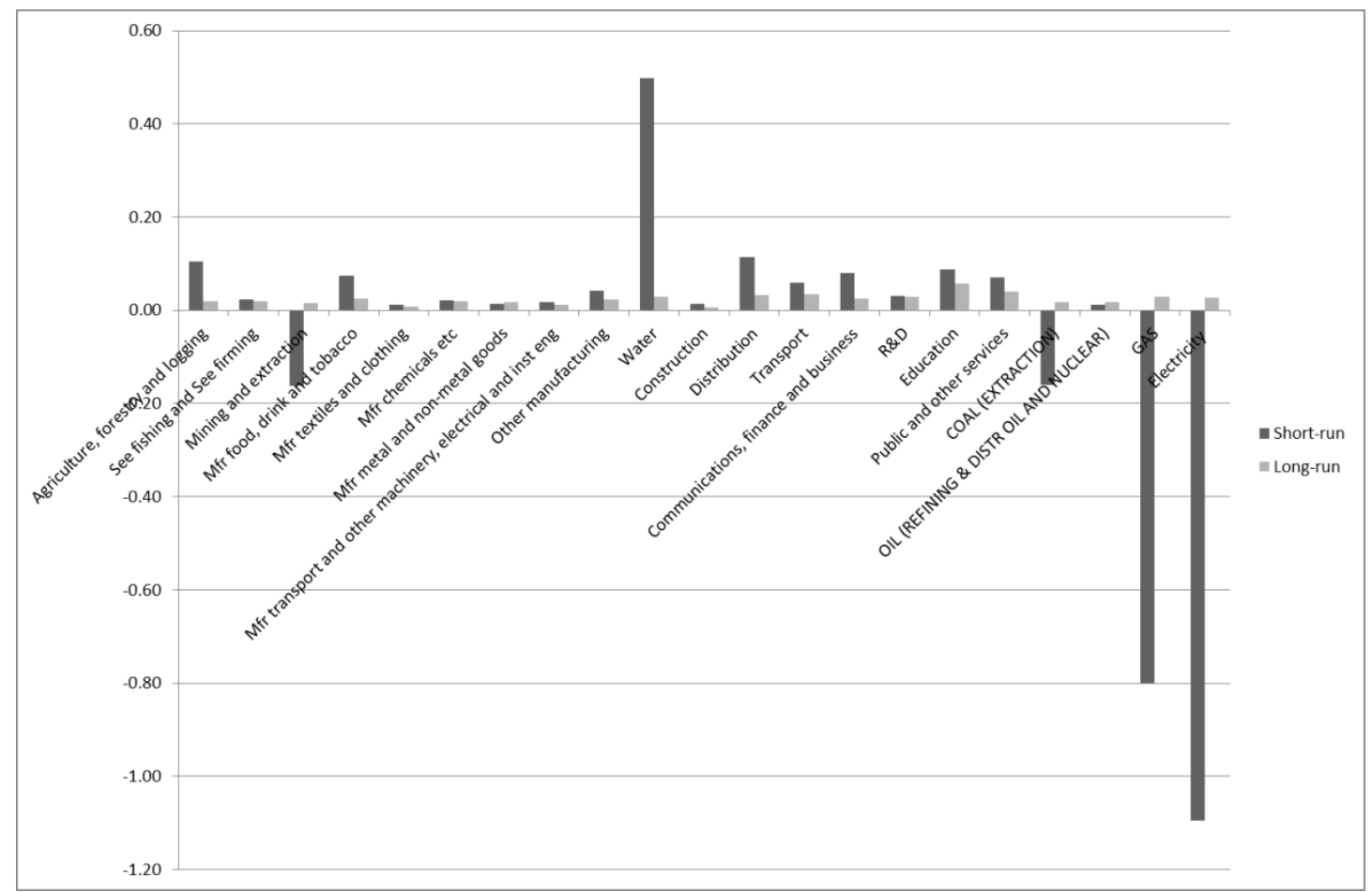

*The results are from simulations using the short-run substitution elasticity in the short-run simulation and the long-run elasticity in the long-run simulation 
Figure $3^{*}$ : Percentage change in output, investment and exports with the standard UKENVI model

\section{Scenario 1}

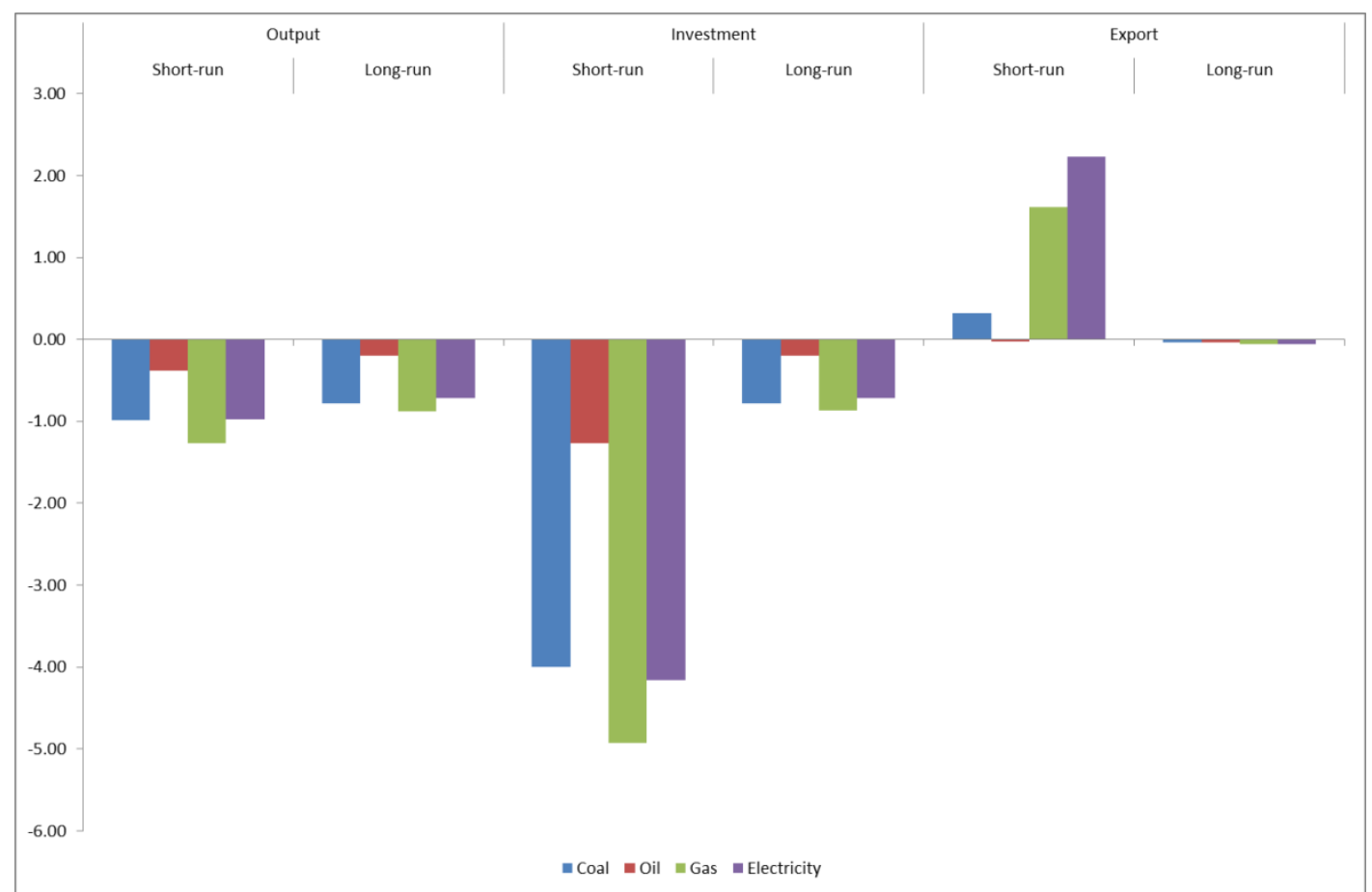

*The results are from simulations using the short-run substitution elasticity in the short-run simulation and the longrun elasticity in the long-run simulation 
Figure 4: Percentage change in commodity prices with the standard UKENVI model and the long-run substitution elasticity

\section{Scenario 1}

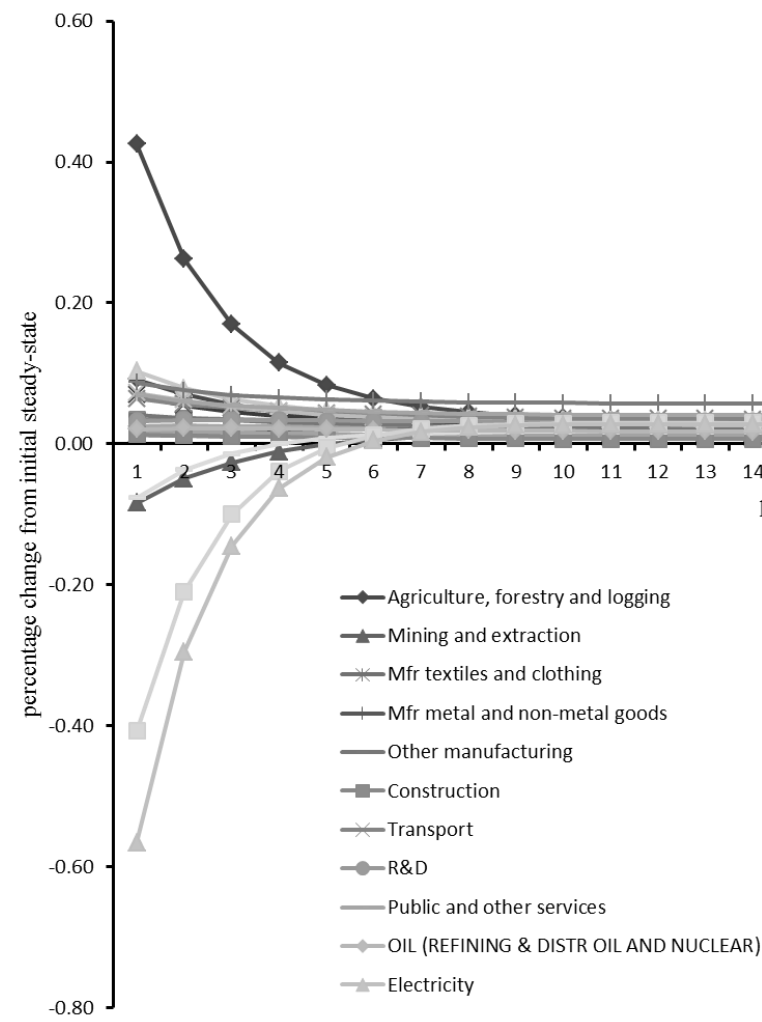

- See fishing and See firming

-Mrr food, drink and tobacco

- Mfr chemicals etc

Mfr transport and other machinery, electrical and inst eng

$\sim$ Water

-Distribution

-Communications, finance and business

- Education

COAL (EXTRACTION)

- GAS 
Figure 5: Percentage change in the replacement cost of capital and the shadow price of capital in the energy sector with the standard UKENVI model and the long-run substitution elasticity

Scenario 1

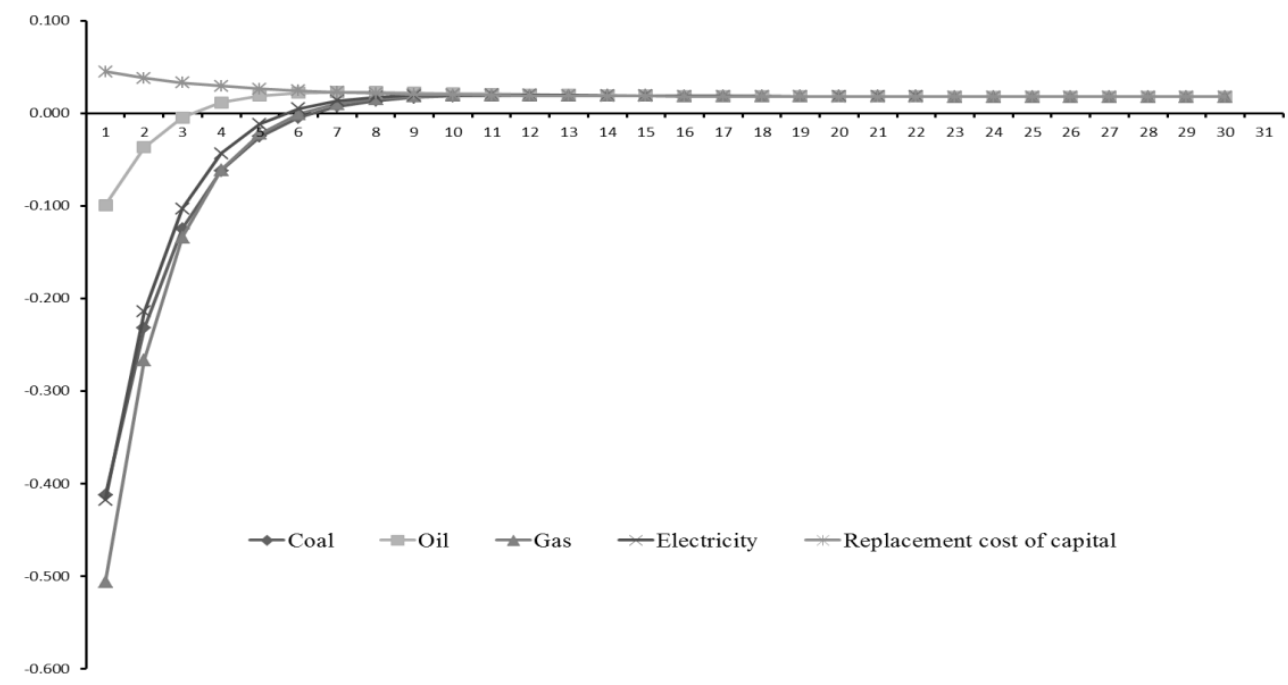


Figure 6: Percentage change in commodity prices with the adjusted UKENVI model and the long-run substitution elasticities

\section{Scenario 2}

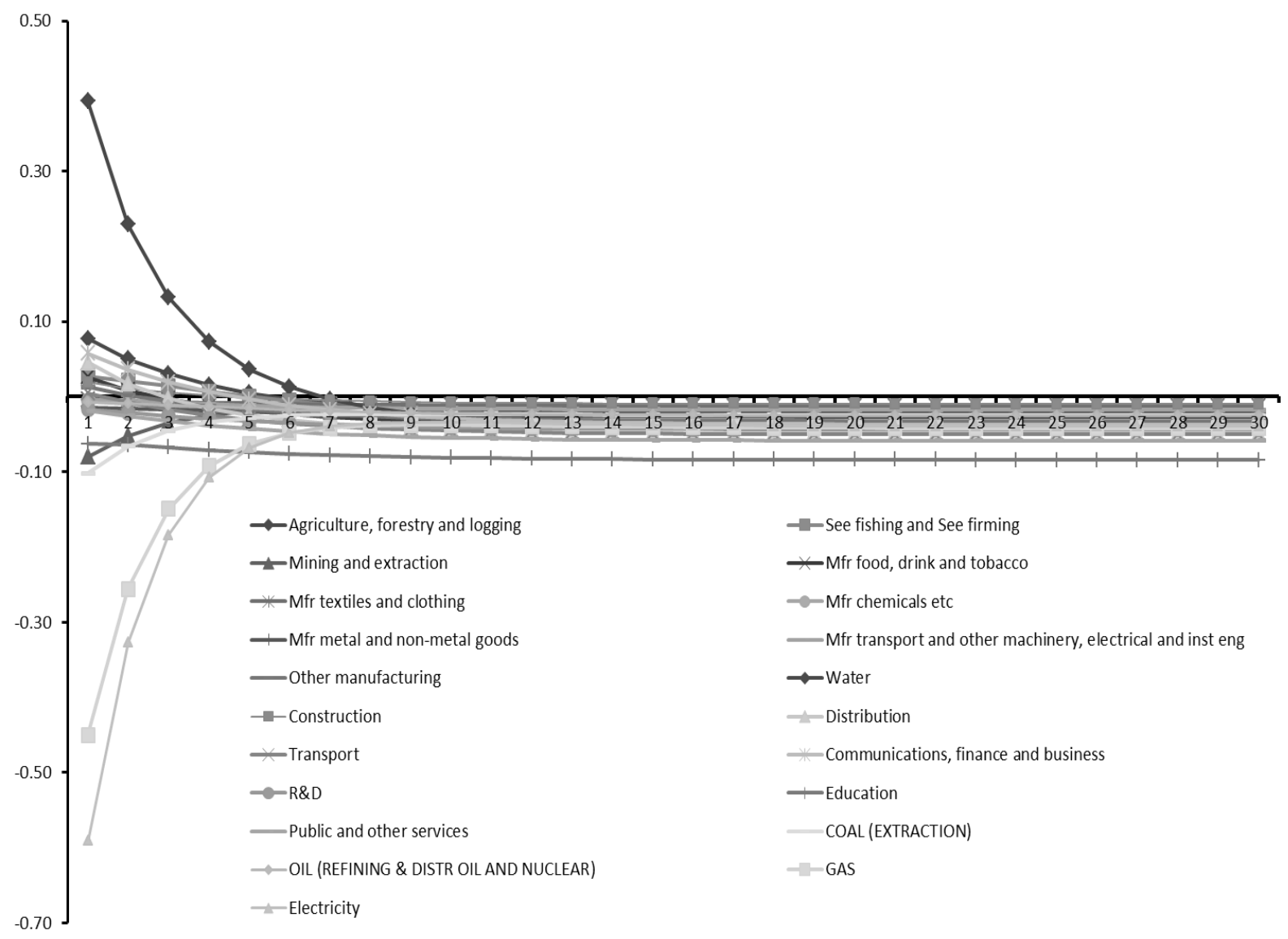




\section{Appendix A: The UKENVI modelling framework}

The general equilibrium simulations in this paper use a variant of the UKENVI CGE model. This is an energy-economy-environment extension of the basic AMOS CGE framework, calibrated on UK data (Allan et al. 2007; Harrigan et al. 1991 and Turner, 2009). In contrast to previous applications of UKENVI, in this version consumption and investment decisions reflect inter-temporal optimization with perfect foresight (Lecca et al. 2013a).

We identify the same twenty one economic activities (commodities/sectors) as considered in the Input-Output analysis in Section 4. There are three domestic transactor groups: government, households and firms. In this application government expenditure is fixed in real terms. Households optimise their lifetime utility, which is a function of consumption $C_{t}$ taking the following form:

$$
U=\sum_{t=0}^{\infty}\left(\frac{1}{1+\rho}\right)^{t} \frac{C_{t}^{1-\sigma}-1}{1-\sigma}
$$

where $C_{t}$ is the consumption at time period $t, \sigma$ and $\rho$ are respectively the constant elasticity of marginal utility and the constant rate of time preference. The intra-temporal consumption bundle, $C_{t}$, is defined, as in the partial equilibrium simulations, as a CES combination of energy and non-energy composites, as given in equation (5) in Section 2. In our empirical analysis we consider consumption of both domestic and imported energy and non-energy goods, where imports are determined through an Armington link and are therefore relativeprice sensitive (Armington, 1969).

The consumption structure is shown in Figure A1. Total consumption is divided in energy and non-energy goods and services. The consumption of energy is then a CES combination of two composites: gas and electricity, and oil and coal. The production structure as imposed in each 
sector is shown in Figure A2, so that the input decisions in each sector involve a hierarchy of CES relationships between inputs of intermediate goods, labour and capital.

The path of investment is obtained by maximizing the present value of the firm's cash flow given by profit, $\pi_{t}$, less private investment expenditure, $I_{t}$, subject to the presence of adjustment cost $g\left(x_{t}\right)$ where $x_{t}=I_{t} / K_{t}$ :

$$
\operatorname{Max} \sum_{t=0}^{\infty} \frac{1}{(1+r)^{t}}\left[\pi_{t}-I_{t}\left(1+g\left(\omega_{t}\right)\right)\right] \text { subject to } \dot{K}_{t}=I_{t}-\delta K_{t}
$$

The solution of the dynamic problem gives us the law of motion of the shadow price of capital, $\lambda_{t}$, and the time path of investment related to the tax-adjusted Tobin's $q$.

The UK labour force is assumed to be fixed, with the real wage determined through a wage function that embodies the econometrically derived specification given in Layard et al. (1991):

$$
\ln \left[\frac{w_{t}}{c p i_{t}}\right]=c-0.068 \ln \left[u_{t}\right]+0.40 \ln \left[\frac{w_{t-1}}{c p i_{t-1}}\right]
$$

where $w, c p i$ and $u$ are the nominal wage after tax, the consumer price index and the unemployment rate respectively, and $c$ is a parameter which is calibrated so as to replicate equilibrium in the base year. In the conventional approach, cpi is simply a function of the price of commodities:

$$
c p i=\operatorname{cpi}\left(p_{N E}, p_{E}\right) \quad c p i_{p_{N E}}, c p i_{p_{E}} \geq 0
$$

where $p_{N E}$ is the price of non-energy goods and services and $p_{E}$ is the price of energy services, both measured in natural units. Finally, in each sector, exports are determined by a standard export demand function. 
However, we need also to impose a number of important behavioural parameters. First, as in all the partial equilibrium simulations, we adopt the estimated values for the short- and longrun elasticity of substitution between energy and non-energy goods and services in household consumption given in Section 3. Trade elasticities are set equal to 2 (Gibson, 1990) and production elasticities equal to 0.3 (Harris, 1989). The interest rate (faced by producers, consumers and investors) is set to 0.04 , the rate of depreciation to 0.15 and with constant elasticity of marginal utility equal to 1.2 (Evans, 2005). 
Figure A.1: The UKENVI model consumption structure

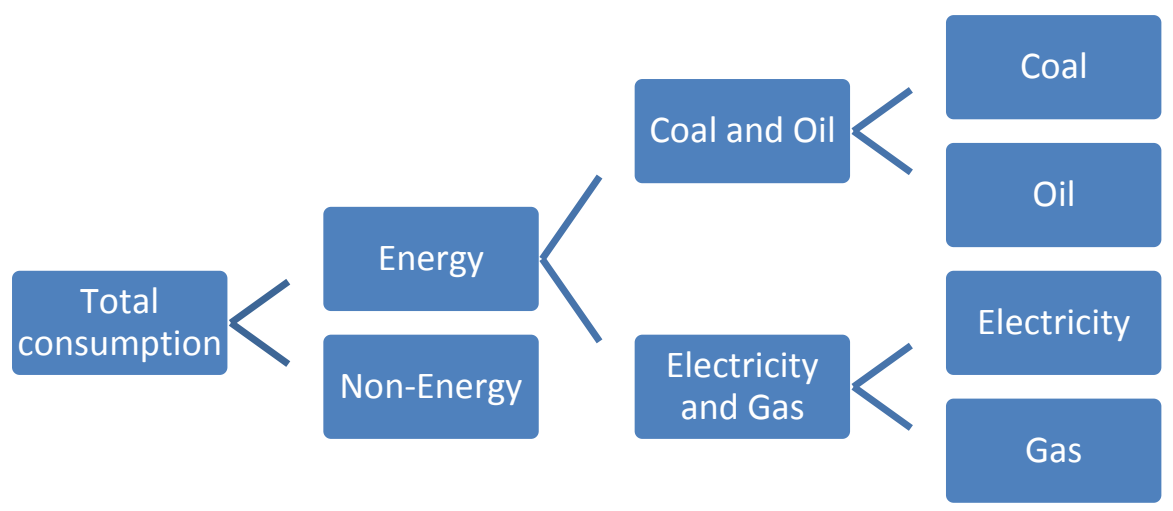

Figure A.2: The UKENVI model production structure for individual sectors

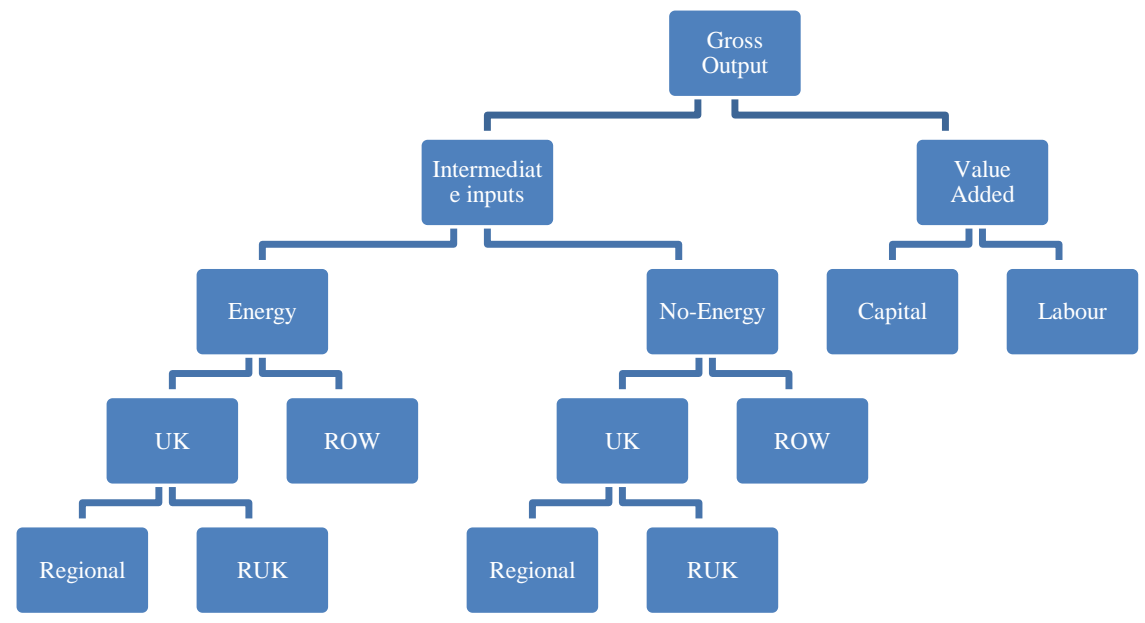

